\title{
Emergency Craniotomy for Extradural Hematoma Evacuation in a Known Case of von Willebrand Disease: Anesthetic Implications
}

\author{
${ }^{1}$ Namita Baldwa, ${ }^{2}$ Sona Dave, ${ }^{3}$ Pinakin Gujjar
}

\begin{abstract}
We report the successful management of an emergency craniotomy performed for extradural hematoma (EDH) evacuation in a known case of von Willebrand disease (VWD).

The case presented a challenge because VWD is associated with extensive bleeding, which was compounded by the emergency nature and type of the surgery. Extensive laboratory investigations could not be carried out, and preoperative optimization was limited.
\end{abstract}

Keywords: Emergency, Extradural hematoma, Von Willebrand disease.

How to cite this article: Baldwa N, Dave S, Gujjar P. Emergency Craniotomy for Extradural Hematoma Evacuation in a Known Case of von Willebrand Disease: Anesthetic Implications. Res Inno in Anesth 2016;1(2):58-60.

Source of support: Nil

Conflict of interest: None

\section{INTRODUCTION}

Von Willebrand disease (vWD) is an inherited disorder, caused by deficiency or dysfunction of von Willebrand factor (vWF), with an estimated prevalence of 0.6 to $1.3 \%$. We report the successful management of an emergency extradural hematoma (EDH) evacuation in a known case of vWD. Perioperative management of the patient was challenging because of emergency nature of surgery, site of surgery, extensive bleeding, and limited resources. Good coordination among the anesthesiologist, the neurosurgeon, and the hematologist is necessary for successful outcome of such cases.

\footnotetext{
${ }^{1}$ Assistant Professor, ${ }^{2}$ Professor, ${ }^{3}$ Professor and Head

${ }^{1-3}$ Department of Anesthesiology, Topiwala National Medical College and BYL Nair Charitable Hospital, Mumbai Maharashtra, India
}

Corresponding Author: Namita Baldwa, Assistant Professor Department of Anesthesiology, Topiwala National Medical College and BYL Nair Charitable Hospital, Mumbai, Maharashtra India, e-mail: drnamita_baldwa@rediffmail.com

\section{CASE REPORT}

A 20-year-old male patient, a known case of seizure disorder and vWD presented with unconsciousness following head injury. He had an episode of generalized tonic-clonic convulsions, following which he had a fall with head injury. On admission to trauma unit, the patient was drowsy, with a Glasgow Coma Scale (GCS) of 10/15 and equal-sized pupils reacting to light. A computed tomography (CT) showed an EDH in the left frontoparietal and parieto-occipital region measuring $9.5 \times 4.3 \times 9 \mathrm{~cm}$ and $6 \times 6 \times 3 \mathrm{~cm}$ respectively, causing a midline shift of $0.8 \mathrm{~cm}$ with mass effect. Thus an emergency surgical decompression was planned.

The patient had a history of seizure disorder and multiple episodes of spontaneous bleeding from the gums since childhood. He was on treatment with oral phenytoin $100 \mathrm{mg}$ (bd) and T. levetericetam $500 \mathrm{mg}$ (bd). He had a prior history of head injury following a convulsion 3 years ago. A CT scan done then showed multiple scalp hematomas. Laboratory investigations done then showed low hemoglobin $(\mathrm{Hb})$ of $5.7 \mathrm{gm} \%$ with a hematocrit of $24.3 \%$, prothrombin time (PT) of $13 / 14$ seconds with an international normalized ratio (INR) of 1.15 and activated partial thromboplastin time (aPTT) of 57 seconds.

On extensive hematological workup, the patient was diagnosed to have vWD. His vWF assay showed a nonreactive antigen (normal range $50-150 \%$ ). He was under regular follow-up with the hematology department and was being transfused four units of cryoprecipitate every fortnightly. He had also been advised oral desmopressin, but the patient was not compliant due to economic constraints.

For the present surgery, an urgent hematological consult was ordered. They advised transfusion of four units of cryoprecipitate preoperatively, intraoperatively and postoperatively. Baseline investigations revealed a $\mathrm{Hb}$ of $6.8 \mathrm{gm} \%$, platelet count of 160,000 , PT of $14 / 12$ seconds, prothrombin index (PI) of 78.45, INR of 1.20 , and aPTT of 50 seconds.

In the operating room, standard monitoring equipment was attached. An 18-gauge intravenous line was secured on the dorsum of the right foot and 4 units of cryoprecipate were transfused. A central venous access 
was secured using a 14/16G venous catheter threaded through the right femoral vein.

The patient was premedicated with intravenous glycopyrrolate $(0.04 \mathrm{mg} / \mathrm{kg})$, ranitidine $(1 \mathrm{mg} / \mathrm{kg})$, ondansetron $(0.08 \mathrm{mg} / \mathrm{kg})$, and sedated with midazolam $(0.03 \mathrm{mg} / \mathrm{kg})$ and fentanyl $(2 \mu \mathrm{g} / \mathrm{kg})$. Tranexamic acid in a bolus dose of $10 \mathrm{mg} / \mathrm{kg}$ followed by a maintenance dose of $1 \mathrm{mg} / \mathrm{kg} /$ hour was started. Induction of anesthesia was done with thiopentone sodium $(5 \mathrm{mg} / \mathrm{kg}$ ) and vecuronium $(0.1 \mathrm{mg} / \mathrm{kg})$. Intravenous lignocaine $(1.5 \mathrm{mg} / \mathrm{kg})$ was given 2 minutes prior to intubation. He was intubated with Portex ${ }^{\circledR}$ endotracheal tube no. 8. Nasogastric tube was inserted orally. Anesthesia was maintained with propofol (150-200 $\mu \mathrm{g} / \mathrm{kg} / \mathrm{hour}$ ) and atracurium boluses.

An extradural clot measuring $800 \mathrm{~mL}$ was evacuated from frontoparietal and occipital region. The estimated blood loss was 1,200 mL. The patient was transfused 2 units of whole blood, 4 units of cryoprecipitate, and 2 units of fresh frozen plasma (FFP) intraoperatively. Fluid replacement was done with 1,000 mL of crystalloid and $500 \mathrm{~mL}$ hydroxyethyl starch. Intraoperative urine output was around $700 \mathrm{~mL}$. The operative time was 180 minutes. The patient was shifted to the Intensive Trauma Care Unit and electively ventilated. At the time of shifting, the patient's hematocrit was 30 . He was transfused 4 units of cryoprecipitate in the immediate postoperative period. On the 2nd postoperative day, patient was conscious, oriented, and responding to verbal commands with a hemoglobin of 8.5, INR of 1.5, and hence extubated. The postextubation patient was hemodynamically stable with a GCS of $15 / 15$.

The patient was transfused 4 units of cryoprecipitate daily for the next 7 postoperative days, as per hematologists' advice. He was put on oral tranexamic acid for 3 weeks. No anti-inflammatory drugs, acetylsalicylic acid, or intramuscular injections were administered perioperatively. He was subsequently discharged and is following up regularly in the hematology department.

\section{DISCUSSION}

Von Willebrand disease is caused by deficiency or dysfunction of vWF, which stabilizes blood coagulation factor FVIII and mediates platelet plug formation through the promotion of platelet-to-platelet and platelet-to-vessel wall adhesion. ${ }^{1,2}$ This inherited disorder has an estimated prevalence of 0.6 to $1.3 \%$ and is classified into three categories: Partial quantitative deficiency (Type 1), qualitative deficiency (Type 2), and total deficiency (Type 3). 1,2 Type 3 disease patients have spontaneous epistaxis or oral mucosal, gastrointestinal, or genitourinary bleeding and no detectable vWF antigen or activity. ${ }^{3}$ Our patient had a totally nonreactive antigen and hence most probably belonged to type 3 .

For the diagnosis, routine coagulation tests, such as PT with INR, aPTT, and, specifically, closure time of collagen/ adenosine diphosphate using platelet function analyzer (PFA-100), coagulation factor VIII (FVIII), vWF antigen (vWF:Ag), and ristocetin cofactor activity (vWF:RCo) are done. In deciding upon the treatment in vWD, it is important to consider the previous bleeding history, FVIII and vWF levels, vWD subtype, response to treatment, and nature of the surgery.

In general surgery, studies suggest that appropriate administration of the FVIII/vWF:RCo concentrates prevents excessive bleeding in more than $90 \%$ of patients. ${ }^{4,5}$ However, the management of patients undergoing neurosurgery with vWD is not well documented. As our patient was posted for an emergency neurosurgery, we had no time for specific investigations (assays) or preoperative optimization.

Strategies to prevent or control bleeding in patients with vWD include the replacement of vWF by human plasma-derived concentrates, administration of desmopressin, which stimulates the release of vWF by endothelial cells, and the use of hemostatic drugs which do not modify the plasma vWF:Ag. ${ }^{14,6,7}$ The preferred therapy is factor VIII plasma concentrate (FVIII) (Humate-Por Alphanate, Grifols, Los Angeles, CA), which, although U.S. Food and Drug Administration approved for hemophilia and not vWD, provides the following corrective components: 2.5 IU vWF:RCo, 1 IU of FVIII, and a nearnormal count of high-molecular-weight multimers. ${ }^{8}$ For our surgery, commercially available recombinant vWF was not available. Thus, the only option available to correct coagulation abnormality was to transfuse cryoprecipitates.

Securing a wide bore venous access proved to be a challenge because the patient had multiple previous punctures and deranged coagulation profile. After transfusing cryoprecipitates, we secured a femoral central venous line. Smooth induction of anesthesia was done keeping a close watch on hemodynamic parameters to avoid any sudden increase in intracranial pressure. As the patient was already having bleeding from the gums, care was taken to avoid any trauma during intubation. Nasogastric tube was inserted from the mouth. Tranexamic acid and head-up position were given to reduce bleeding intraoperatively.

Correction of coagulation defect was done with cryoprecipitates and FFP. Cryoprecipitate is administered in a dose of 1 unit/5-6 kg, which raises the Factor VIIIC level by 15 to $20 \%$. During the intraoperative period, the consumption of vWF is increased and may require 
subsequent administration of cryoprecipitate as frequently as every 6 to 8 hours. During perioperative period of a major surgery, factor VIII activity and vWF activity should be kept at adequate levels (factor VIII: 105-150\%; vWF: 65-225\%). ${ }^{9}$

Fresh frozen plasma corrects the abnormality similar to cryoprecipitate, but volume administered may be associated with circulatory overload. Usually, $20 \mathrm{~mL} / \mathrm{kg}$ FFP, every 8 hours, controls clinical bleeding. But, we had to administer FFP due to limited availability of cryoprecipitate.

Although desmopressin is recommended as the treatment of choice for patients with type $1 \mathrm{vWD}$, it was not administered to our patient as he probably belonged to type 3 disease, where it is ineffective. Tranexamic acid was administered as an adjunct to FVIII/vWF:RCo concentrates. Its antifibrinolytic drug inhibits the conversion of plasminogen into plasmin and stabilizes clots that have been formed. ${ }^{10}$

Without objective tests, it was difficult to assess the adequacy of coagulation function intraoperatively. As it was a closed compartment surgery, any bleeding could result in adverse clinical outcome. Continuous bleeding in the cutaneous surgical field is usually due to poor control of severed vessels, whereas disorders of hemostasis tend to manifest with recalcitrant diffuse slow oozing within the operative site. Therefore, careful dissection and bipolar electrocautery have been proposed to control bleeding, which were used by our neurosurgeons to ensure hemostasis. ${ }^{11}$

Postoperatively, the patient was administered cryoprecipitate to maintain vWF levels in the immediate postoperative period. The patient was observed for any signs of neurological deterioration.

\section{CONCLUSION}

Collaboration among the anesthesiologist, the neurosurgeon, and the hematologist is important for successful outcome. Clinical acumen and strict vigilance is the key to handling such patients on emergency basis, in the face of limited resources.

\section{REFERENCES}

1. Nichols WL, Hultin MB, James AH, Manco-Johnson MJ, Montgomery RR, Ortel TL, Rick ME, Sadler JE, Weinstein M, Yawn BP. Von Willebrand disease (VWD): evidence-based diagnosis and management guidelines, the National Heart, Lung, and Blood Institute (NHLBI) Expert Panel report (USA). Haemophilia 2008 Mar;14(2):171-232.

2. Budde U. Diagnosis of von Willebrand disease subtypes: implications for treatment. Haemophilia 2008 Nov;14 (Suppl 5): 27-38.

3. Handin RI. Disorder of the platelet and vessel wall. In: Braunwald E, Fauci AS, Kasper DL, Hauser SL, Longe DL, Jameson JL, editors. Harrison's principles of internal medicine. 15th ed. Vol. 116. New York (NY): MaGraw-Hill; 2002. p. 747-748.

4. Mannucci PM. Treatment of von Willebrand's disease. N Engl J Med 2004 Aug 12;351(7):683-694.

5. Thompson AR, Gill JC, Ewenstein BM, Mueller-Velten G, Schwartz BA. Successful treatment for patients with von Willebrand disease undergoing urgent surgery using factor VIII/VWF concentrate (Humate-P). Haemophilia 2004 Jan;10(1):42-51.

6. Gröner A. Pathogen safety of plasma-derived products Haemate P/Humate-P. Haemophilia 2008 Nov;14 (Suppl 5): 54-71.

7. Kreuz W. von Willebrand's disease: from discovery to therapymilestones in the last 25 years. Haemophilia 2008 Nov;14 (Suppl 5):1-2.

8. United Kingdom Haemophilia Centre Doctors' Organisation (UKHCDO). Guidelines on the selection and use of therapeutic products to treat haemophilia and other hereditary bleeding disorders. Haemophilia 2003 Jan;9(1):1-23.

9. Gerling V, Lahpor JR, Buhrel W. Peri-operative management of an adult patient with type $2 \mathrm{~N}$ von Willebrand's disease scheduled for coronary artery bypass graft. Anaesthesia 2007 Apr;62(4):405-408.

10. Mahdy AM, Webster NR. Perioperative systemic haemostatic agents. Br J Anaesth 2004 Dec;93(6):842-858.

11. Jiménez-Yuste V, Prim MP, De Diego JI, Villar A, Quintana M, Rabanal I, Sastre N, Hernández-Navarro F. Otolaryngologic surgery in children with von Willebrand disease. Arch Otolaryngol Head Neck Surg 2002 Dec;128(12):1365-1368. 